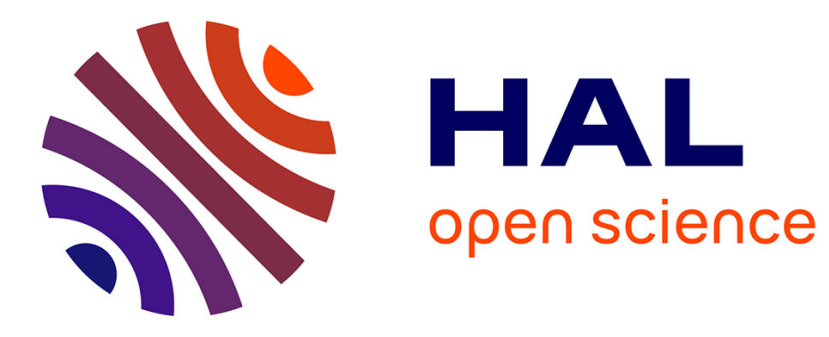

\title{
Le monde sous globe ou la fin de l'aventure \\ Martyne Perrot
}

\section{To cite this version:}

Martyne Perrot. Le monde sous globe ou la fin de l'aventure. Communications, 1989, 49 (La mémoire et l'oubli), pp.207-211. halshs-00376615

\section{HAL Id: halshs-00376615 https://shs.hal.science/halshs-00376615}

Submitted on 18 Apr 2009

HAL is a multi-disciplinary open access archive for the deposit and dissemination of scientific research documents, whether they are published or not. The documents may come from teaching and research institutions in France or abroad, or from public or private research centers.
L'archive ouverte pluridisciplinaire HAL, est destinée au dépôt et à la diffusion de documents scientifiques de niveau recherche, publiés ou non, émanant des établissements d'enseignement et de recherche français ou étrangers, des laboratoires publics ou privés. 


\title{
Le monde sous globe
}

\author{
ou \\ la fin de l'aventure
}

Depuis longtemps je me vantais de posséder tous les paysages possibles, et trouvais dérisoires les célébrités de la peinture et de la poésie modernes.

Jaimais les peintures idiotes, dessus de portes, décors: toiles de saltimbanques, enseignes, enluminures populaires $\lfloor\ldots\rfloor$.

Arthur Rimbaud (line saison en enfer)

Lorsque le souvenir de Rosebud apparaît à Kane à l'intérieur d'une boule neigeuse, se formule l'énigme d'une vie qui s'achève en cette aube de l'année 1940. Orson Welles a élu cet objet naïf et enfantin pour mettre en scène la métaphore de la mémoire.

Souvenirs d'enfance ou témoins du monde, les boules de neige jouent désormais les classiques parmi la multitude d'objets que le marché touristique produit aujourd'hui. L'histoire de leur invention n'est pas faite, car, méprisées comme la plupart des «souvenirs » de ce genre, elles échappent aux classements esthétiques et anthropologiques. Leur vulgarité dévalorisant toute signification, sinon celle du mauvais goût, seuls les ouvrages consacrés au kitsch en font mention. Mais elles sont alors traitées d'un point de vue formel : leur fonction mnémonique, c'est-à-dire ce dont elles témoignent et ce qu'elles transmettent, est toujours oubliée. Pourtant, que la neige tombe sur les palmiers de Miami ou sur la tour Eiffel, c'est par milliers que se confectionnent aujourd'hui, entre Hong Kong et Macao, ces petites sphères de plastique. Existerait-il un secret propre à ces objets qui, toujours liés au voyage, survivent en marge du récit?

Sans doute faut-il d'abord questionner ce témoignage candide qu'elles incarnent. Leur vertu première est en effet d'affirmer : « J'y étais et en voici la preuve », laquelle, posée négligemment sur une 


\section{Martyne Perrot}

étagère, réactualise au jour le jour les vacances aux Baléares ou la visite du Mont-Saint-Michel. Expliquer l'engouement pour ces «souvenirs » par la commémoration quotidienne qu'ils imposent n'épuise pas cependant la richesse de leurs évocations. Ces bulles de verre ou de plastique seraient-elles les derniers avatars d'un désir d'aventure qui trouverait là ses ultimes lieux de résistance désuets et dérisoires? C'est en effet ce qui semble émaner d'elles lorsque, l'esprit rêveur et l'âme nonchalante, on se laisse aller à une contemplation non conformiste.

Objets destinés aux enfants, les boules neigeuses sont aussi les derniers vestiges d'une certaine "enfance du monde": celle que construisirent, en le parcourant, des voyageurs illustres comme Marco Polo ou Ibn Batoutah. L'enfance du monde correspond à cette, période d'émerveillement créée par la découverte de terres vierges. Les sites décrits ne sont-ils pas toujours fantastiques, les animaux fabuleux, les plantes incroyables? Les émotions excessives font alors l'ordinaire de la découverte et le monde s'invente à chaque pas. Si Marco Polo réunit ses récits de voyage sous le titre Le Livre des merveilles, c'est parce qu'il n'existe pas de qualificatif plus dense pour décrire les sensations et les souvenirs de son périple. La mémoire du voyageur, se mêlant à l'imagination de l'artiste chargé d'illustrer la relation de voyage, fait alors entrer celle-ci dans le monde du rêve et participe à la création des paradis exotiques.

Au Xvi" siècle, les gravures de Théodore de Bry traduisent bien, pour l'Inde, cet imaginaire baroque et foisonnant : abondance de la nature, jungle impénétrable, poissons, oiseaux et racines merveilleuses agrémentent le récit. C'est aussi cette vision du monde et de la nature que vont incarner, à la même époque, les cabinets de curiosité, "microcosme et abrégé de l'univers '", qui contenaient tout ce qui animait la quête du voyageur et son goût pour les choses rares. Les boules neigeuses sont-elles les héritières triviales et bâtardes de ces « chambres des merveilles »? Sans doute, car sous la sphère transparente, lorsqu'à volonté les chutes de neige ou les pluies d'étoilés inondent le paysage "peint à la main ", chacun pénètre une dernière fois le paradis perdu. Mais l'émerveillement ne semble plus être à la mode depuis le XVII' siècle, époque marquée par la naissance de l'histoire naturelle. L'extase et l'effroi disparaissent aussi, alors que l'amateur remplace le curieux et que les premiers sites touristiques font leur apparition ${ }^{2}$. Le $x x^{\prime \prime}$ siècle, lui, offre donc aux touristes ces petites sphères dont le diamètre n'excède pas dix centimètres, car jamais ces objets n'ont eu la prétention de grossir. Leur ambition, pourtant, est aussi vaste que leur taille est réduite. La miniaturisa- 
tion permet de saisir site et monument d'un seul coup d'œil, de les tenir également dans le creux de la main. Tel un dieu, tel un souverain. L'illusion du poids du monde et de sa domination est ainsi proposée au touriste qui réaffirme à son insu que la terre est ronde et renoue avec cette représentation du monde que les Grecs avaient pressentie dès le $\mathrm{Vi}^{\mathrm{r}}$ siècle. Sphériques et enchantées, les boules neigeuses sont le dernier chaînon de ce lignage oublié, et nous supposons qu'elles tirent de lui leur irrésistible séduction.

La fascination immédiate qu'elles provoquent est cependant prise au piège, car la sphère cristalline est aussi une prison transparente; ultime aveu de nos fantasmes d'aventure, elle encercle nos désirs, les figeant sous forme d'un monde englouti. L'eau qui baigne ces paysages miniatures n'évoque-t-elle pas une Atlantide de poche? Succédané probable de cette mythologie, elle noie nos derniers rêves de mondes mystérieux dans une mise en scène de pacotille. La rotondité du monde et sa clôture sont indissolublement liées dans l'univers de ces "souvenirs": si la sphère est pour les mathématiques la forme parfaite, elle est aussi la plus close. Antérieurement, il y eut à Paris la mode des panoramas, peints en trompe l'œeil et regardés du centre. Ils révélaient déjà cette envie de maîtriser le monde tout en ne s'y perdant plus. En cela, la boule de neige est un objet exotique, elle arraisonne en pleine ville toutes les dérives imaginaires et met sous globe les signes d'une aventure possible. Comme l'exotisme, elle hante les salons bien qu'on la juge moins distinguée.

Si elle illustre la fin de l'aventure, la boule neigeuse reste néanmoins source d'émerveillement : elle provoque cette rêverie instantanée si chère à Bachelard. Les réminiscences qu'elle offre sont celles de l'enfance : le ciel toujours bleu éveille en effet « un narcissisme spécial, le narcissisme de la pureté ${ }^{3}$ ». Autre élément magique, la neige est en étroite connivence avec cette période de la vie. "Dans les contes souvent, seuls les enfants sont initiés aux mystères de la neige " ${ }^{*}$. Contempler la neige qui tombe sur ces paysages peints à la main invite ainsi au voyage dans l'inconnu et au retour aux origines, et l'alliance eau/neige est d'une grande efficacité symbolique : dans cette eau laiteuse, proche du liquide amniotique, vont naître de nouveaux mondes, ou plutôt leur parodie.

Tous ces éléments offerts à la délectation du touriste explique sans doute que, souvenirs parmi d'autres, les boules de neige l'attendent encore à la fin du voyage. Rançon et trophée de la course au bout du monde, totem anonyme qui ne représente plus que lui-même, elles mythologisent pourtant notre quotidien, comme le kitsch auquel elles sont indéniablement liées, "qu'il s'agisse des guirlandes de 


\section{Martyne Perrot}

Tahiti, des gondoles de Venise ou des Écossais en kilt ${ }^{5}$ ». Le souvenir mythifie pour compenser l'absence de risque qui caractérise aujourd'hui l'itinéraire touristique. Ni intime ni étranger, il ménage le confort moral et intellectuel du vacancier, lui évite les remords de l'inculture et berce sa mémoire au rythme lent des chutes de neige et des pluies d'étoiles. La mise en scène est inexorablement la même pour tous, monument, paysage, personnage célèbre ou animal. Inexorablement, elle défie la météorologie, la géographie et l'histoire. Elle oublie le contexte pour célébrer des lieux déjà stéréotypés et abordés avant que le voyageur ait eu à appareiller. Mis sous globe comme des coiffes de mariées, ces lieux certifient que le touriste n'a négligé aucun de ces endroits "à voir », non à découvrir ni à contempler. La contemplation n'est plus en fait que celle de l'objet lui-même, qui assure, comme les guides, que chaque étape a été atteinte. Il rappelle la mémoire à l'ordre, comme les cartes postales, qui incitent à la visite plus qu'elles ne récompensent de l'avoir effectuée. Qui ne connaît, en effet, cette impression d'avoir manqué un spectacle lorsque le tourniquet des cartes postales révèle un point de vue qui vous a échappé ? Entre le lieu et son souvenir n'existe aucun lien, sinon celui du nom qui l'authentifie. Aussi n'est-il pas rare, avec l'industrialisation de la fabrication, de découvrir des représentations étranges, comme cette tour de Toronto située en plein centre de Los Angeles, due à l'étourderie d'un ouvrier de Macao?

Au début du siècle, certaines cartes postales servaient quelquefois à illustrer des régions différentes. Aux dires d'un de ces photographes de paysages, une même photo portait des légendes différentes, et de citer le cas d'un paysage auvergnat indûment réutilisé pour représenter les Alpes ${ }^{6}$. Nul ne songerait à s'en offusquer, car l'espace comme le temps semblent pétrifiés. On peut dater le souvenir en tant qu'objet, mais le paysage ou le monument qu'il figure semblent frappés d'éternité. La répétition à l'identique et à grande échelle en est une des causes. Des milliers de Taj Mahal ou de tours Eiffel anéantissent ou éternisent le sujet représenté. Si l'histoire s'efface devant le nombre, c'est qu'à l'intérieur des boules de neige les lieux n'ont plus d'origine : ils sont sans âge. Objets d'une reproduction compulsive, l'arc de Triomphe ou le Parthénon semblent parfois moins réels que leurs modèles réduits. Ces minuscules effigies sont les symptômes envahissants d'une histoire touristique récente qui, parfois, se confond avece l'histoire du monument lui-même. Il y a d'ailleurs, à y songer, quelque chose de primitif dans cette prolifération sauvage, cette fertilité non maîtrisée. Sites et monuments, semblables au dieu Aa des îles Australes exhibant son envahissante progéniture, offrent 
à la consommation du touriste cette descendance amnésique. Ces souvenirs sont en effet déracinés dès leur naissance, et dans les fabriques asiatiques se dissolvent le temps et l'espace, le patrimoine et la généalogie.

Si les boules neigeuses ne célèbrent pas le génie du lieu, elles ont celui du déplacement. Étrange aller et retour, de Hong Kong à Paris, effectué par cet arc de Triomphe sous globe qu'a rapporté dans ses valises un touriste chinois. L'aventure, on le voit, est aujourd'hui d'abord celle de l'objet qui la met en scène ; l'exotisme aussi, qui naît de ce croisement étrange et ironique des lieux et des savoir-faire. Dans son essai sur ce thème, Victor Segalen écrivait que le " tourisme avait commencé dès que l'on sut que le monde ressemblait à une boule ? ". Ce « désenchantement propre au monde sphérique par rapport à l'étendue plate "que les hommes avaient imaginée est-il responsable aujourd'hui de la monotonie des souvenirs, dont la moitié émergent à l'intérieur de sphères de plastique ? Et ces petits globes seraient-ils, sans le savoir, des mappemondes qui compenseraient la nostalgie du monde plat? Il reste que derrière la paroi transparente s'opère l'anamorphose d'une époque pour laquelle les souvenirs de l'âge d'or et du paradis perdu ressemblent à des bulles de savon.

Martyne PERroT

\section{NOTES}

1. Krysztof Pomian, Collectionneurs amateurs et curieux. Paris, Venise : 16"-18 siècle, Paris, Gallimard, 1987, p. 64.

2. Ibid., p. 61 .

3. Gaston Bachelard, L'Air et les Songes. Essai sur l'imagination du mouvement, Librairie José Corti, 1950, p. 186.

4. Martin de La Soudière, L'Hiver. A la recherche d'une morte saison, Lyon, La Manufacture, 1987, p. 208.

5. Gillo Dorfles, Le Kitsch. Un catalogue raisonné du mauvais goût, Paris, Éd. Complexe, 1978, p. 177 (trad. de l'italien par Paul Alexandre).

6. A. Ripert et Cl. Frère, La Carte postale, son histoire, sa fonction sociale, Éd. CNRSPUL, 1984, p. 78.

7. Victor Segalen, Essai sur l'exotisme. Une esthétique du divers, Paris, Fata Morgana, 1978. 